\title{
A METÁTESE NA VARIEDADE DO INTERIOR PAULISTA
}

\section{METATHESIS IN THE VARIETY OF THE INLAND OF SÃO PAULO STATE}

\author{
Jheniffer Amanda Dias* \\ https://orcid.org/0000-0002-1286-1532. \\ Universidade Federal do Paraná \\ Márcia Cristina do Carmo** \\ https://orcid.org/0000-0003-0546-7622. \\ Universidade Estadual de Ponta Grossa
}

\begin{abstract}
Resumo: Este trabalho analisa o fenômeno fonético-fonológico denominado metátese na variedade do interior paulista, mais precisamente no Noroeste do estado. Por meio desse fenômeno, antigo na língua portuguesa, ocorre a inversão na ordem linear dos sons, como, por exemplo, em sa.tis. fa.ção sas.ti.fa.ção. Embasando-se nos pressupostos da Teoria da Variação e Mudança Linguística (LABOV, 2008), foram investigadas 48 entrevistas retiradas do banco de dados IBORUNA (Projeto Amostra Linguística do Interior Paulista - ALIP - GONÇALVES, 2021 [2007]), com o objetivo de verificar os possíveis condicionadores linguísticos e extralinguísticos que motivam a presença do fenômeno. Como resultado, foram encontradas 18 ocorrências de metátese. Desses casos, 11 eram metáteses progressivas; seis, regressivas; e uma, recíproca. Observou-se, também, que a maioria das ocorrências envolve /r/ e são de metátese perceptual. Em relação às variáveis extralinguísticas, o fenômeno teve maior aplicação em informantes do sexo/gênero masculino; com a faixa etária superior a 55 anos; e nível de escolaridade com o $2^{\circ}$ Ciclo do Ensino Fundamental, o que parece fornecer indícios de estigma social.
\end{abstract}

Palavras-chave: Português brasileiro. Variação e mudança linguística. Fonética e Fonologia. Metátese.

\begin{abstract}
This work analyzes the phonetic-phonological phenomenon named metathesis in the variety spoken in the inland of São Paulo, more precisely in the Northwest of the state. Through
\end{abstract}

\footnotetext{
${ }^{*}$ Mestranda em Estudos Linguísticos pela Universidade Federal do Paraná (UFPR), bolsista da Coordenação de Aperfeiçoamento de Pessoal de Nível Superior (Capes). Licenciada em Letras (Português/Espanhol) pela Universidade Estadual de Ponta Grossa (UEPG). E-mail: <jhenifferamandadias@gmail.com>.

** Docente adjunta vinculada ao Departamento de Estudos da Linguagem (DEEL) da Universidade Estadual de Ponta Grossa (UEPG). Pós-doutorado em Estudos Linguísticos na University College London (UCL/Reino Unido). Doutora e Mestre em Estudos Linguísticos pela Universidade Estadual Paulista (Unesp/Ibilce). Licenciada em Letras (Português/Inglês - Unesp/Ibilce). E-mail: mccarmo@uepg.br.
} 
this phenomenon, ancient in Portuguese, there is an inversion in the linear order of sounds such as sa.tis.fa.ção sas.ti.fa.ção ('satisfaction'). Based on the assumptions of the Linguistic Variation and Change Theory (LABOV, 2008), 48 interviews from the IBORUNA database (Projeto Amostra Linguística do Interior Paulista - ALIP - [Linguistic Sample from Inland of São Paulo] GONÇALVES, 2021 [2007]), were investigated in order to verify possible linguistic and extralinguistic conditioners that motivate the phenomenon. As a result, 18 metathesis occurrences were found. Of these cases, 11 were progressive metathesis, six regressive and one reciprocal. It was also observed that most of the occurrences involve / $\mathrm{r} /$ and are classified as perceptual metathesis. In respect of extralinguistic variables, the phenomenon is more frequent in the speech of masculine sex/gender ( $72 \%$ of the cases); in the age group older than 55 years old; and level of education of the second cycle of Elementary Education, which seems to provide evidence of social stigma.

Keywords: Brazilian Portuguese. Linguistic variation and change. Phonetics and Phonology. Metathesis.

\section{Introdução}

Este artigo ${ }^{1}$ objetiva analisar sincronicamente o fenômeno fonético-fonológico denominado metátese no Português Brasileiro (PB), especificamente na variedade falada no interior do estado de São Paulo. Por meio da metátese, ocorre a “[...] inversão na ordem linear dos sons sob certas condições” (HORA; TELLES; MONARETTO, 2007, p. 178), como, por exemplo, em a.ce.lo.ra a.ce.ro.la, pa.tro pra.to, pre.da pe.dra e sas.ti.fa.ção sa.tis.fa.ção. ${ }^{2}$

A transposição de segmentos dentro de uma palavra é um fenômeno antigo na língua portuguesa, havendo registros de formas derivadas por metátese desde a passagem do latim para o português, como em pre.gun.tar per.gun.tar (ARAÚJO, 2011). Todavia, são escassos os estudos sincrônicos sobre esse fenômeno no PB (HORA; TELLES; MONARETTO, 2007; HORA; TELLES, 2019) e inexistentes no que tange à variedade do interior paulista. Destacase, desse modo, o caráter inédito deste trabalho.

A complexidade da metátese é destacada por Hume (2002), pois, embora a variação no ordenamento linear dos elementos seja relativamente recorrente na sintaxe, essa variação não é usual na fonologia. Segundo a autora, a metátese se difere da maioria dos fenômenos fonético-fonológicos, já que estes costumam ter, como alvo, um único som, o qual sofre uma alteração em um contexto específico, o que não ocorre na metátese. Desse modo, por muito tempo, a metátese foi concebida como um processo aleatório e irregular, correspondente a um mero "erro" de pronúncia, o que tem sido contestado por trabalhos atuais sobre o tema (ARAÚJO, 2011; HORA; TELLES, 2019; HORA; TELLES; MONARETTO, 2007). Com base na literatura, trata-se de um fenômeno recorrente na produção da fala de crianças em fase de aquisição da

\footnotetext{
${ }^{1}$ O presente artigo apresenta os resultados principais do Trabalho de Conclusão de Curso (TCC) intitulado Acobracias da língua(gem): a metátese no noroeste paulista (DIAS, 2020), defendido pela primeira autora, sob orientação da segunda, na Universidade Estadual de Ponta Grossa (UEPG).

${ }^{2}$ Nos exemplos apresentados, o ponto indica divisão silábica.
} 
linguagem (HORA; TELLES, 2019), o que suscita a hipótese inicial deste trabalho: a de que esse fenômeno ocorreria com maior frequência na fala de informantes mais jovens, pertencentes à faixa etária de 7 a 15 anos do banco de dados analisado, posto que ainda não atingiram o denominado período crítico de aquisição da linguagem. ${ }^{3}$

O presente estudo conduz uma pesquisa sincrônica, embasando-se nos pressupostos da Teoria da Variação e Mudança Linguística (LABOV, 2008). Sincronicamente, Hora, Telles e Monaretto (2007) constatam uma tendência conservadora da metátese no PB. A partir da investigação das ocorrências do fenômeno estudado em manuscritos do PB dos séculos XVII a XXI, os autores afirmam que suas escassas ocorrências decorrem de variedade não-padrão ou de mudanças já lexicalizadas. Diacronicamente, os autores destacam a natureza regular e não aleatória da metátese no PB.

Como corpus, são analisadas amostras de fala espontânea retiradas do banco de dados IBORUNA(GONÇALVES, 2021 [2007]), resultado do Projeto Amostra Linguística do Interior Paulista (ALIP) - Processo FAPESP 03/08058-6. A escolha pela variedade do interior paulista - especificamente do Noroeste do estado - e, consequentemente, pela utilização desse banco de dados justifica-se pelo preenchimento da lacuna existente em relação a estudos de metátese na variedade analisada. ${ }^{4}$

Do banco de dados IBORUNA, foram analisados, nesta pesquisa, dois sexos/gêneros (feminino e masculino); duas faixas etárias (de 7 a 15 anos e acima de 55 anos); e três escolaridades ( $1^{\circ}$ Ciclo do Ensino Fundamental - doravante, EF -, $2^{\circ}$ Ciclo do EF e Ensino Médio). Para cada perfil social, foram analisados inquéritos de quatro informantes. A partir da combinação desses fatores sociais ( $2 \times 2 \times 3 \times 4$ ), totalizaram-se 48 entrevistas investigadas.

Com a condução desta pesquisa, busca-se verificar possíveis condicionadores linguísticos e extralinguísticos para as ocorrências de metátese na fala espontânea do interior paulista, contribuindo para o mapeamento dos processos fonético-fonológicos nessa variedade e, de modo mais abrangente, do PB.

O presente trabalho está estruturado da seguinte forma: a próxima seção conta com uma breve discussão acerca da Teoria da Variação e Mudança Linguística (LABOV, 2008) e uma descrição do fenômeno estudado, abordando, também, a metátese em estudos diacrônicos. Em seguida, apresentam-se informações sobre o material e os métodos empregados. Por fim, é realizada a análise dos dados levantados, seguida pelas considerações finais e pelas referências bibliográficas.

\footnotetext{
${ }^{3} \mathrm{O}$ período crítico de aquisição da linguagem consiste na hipótese de que a aquisição da linguagem ocorre dos dois anos até a idade da puberdade e, após essa fase, a língua do falante fica essencialmente estável (LIMA JÚNIOR, 2013). Após o período crítico, a gramática utilizada pelo falante não sofre mudanças significativas e quaisquer mudanças seriam esporádicas. Dessa maneira, conforme salienta Naro (2013), uma pessoa adulta faz uso de uma gramática adquirida quando tinha, aproximadamente, 15 anos de idade. "Assim sendo, a fala de uma pessoa com 60 anos hoje representa a língua de quarenta e cinco anos atrás [...]" (NARO, 2013, p. 45).

${ }^{4}$ Ademais, destaca-se o fato de o banco de dados IBORUNA já ter passado por Comitê de Ética durante sua constituição, não tendo sido necessária a submissão do projeto deste trabalho a Comitê de Ética em Pesquisa (CEP).
} 


\section{Fundamentação teórica}

Nesta seção, são apresentados tópicos que fornecerão auxílio para esclarecer conceitos fundamentais sobre o arcabouço teórico que embasa esta pesquisa. No primeiro, Teoria da Variação e Mudança Linguística, é realizado um breve apanhado dessa teoria, também denominada Sociolinguística Variacionista, proposta por Labov (2008). No segundo, Metátese, há uma explanação do processo estudado, seguido por descrições feitas a partir de estudos diacrônicos no PB.

\section{Teoria da Variação e Mudança Linguística}

Esta pesquisa é teoricamente fundamentada na Sociolinguística laboviana, denominada Teoria da Variação e Mudança Linguística (LABOV, 2008), ${ }^{5}$ que tem, como objeto de estudos, a língua concebida como um sistema heterogêneo, variável e social, cuja "[...] heterogeneidade não é apenas comum, ela é o resultado natural de fatores linguísticos fundamentais” (LABOV, 2008, p. 238).

As formas linguísticas em variação são classificadas como variantes linguísticas, e, a um conjunto de variantes, dá-se o nome de variável. A escolha do falante por uma ou outra variante obedece a um padrão sistematizado por regras (TARALLO, 2003), consistindo, portanto, em uma heterogeneidade ordenada. De acordo com Weinreich, Labov e Herzog (2006, p. 36, grifo dos autores), “[...] numa língua que serve a uma comunidade complexa (i.e., real), a ausência de heterogeneidade estruturada é que seria disfuncional”.

De acordo com Weinreich, Labov e Herzog (2006), há cinco problemas com os quais os estudos sobre mudança linguística devem lidar: (i) fatores condicionantes, que dizem respeito às condições possíveis para mudanças que podem ocorrer em determinada estrutura linguística; (ii) transição, que analisa estágios intervenientes entre duas formas linguísticas em épocas diferentes, em uma mesma comunidade de fala; (iii) encaixamento, relativo à associação concomitante de determinadas mudanças a outras; (iv) avaliação, referente aos correlatos subjetivos de estruturas linguísticas heterogêneas; e (v) implementação, considerada pelos autores como a mais fundamental, correspondente à busca pela justificativa de determinada mudança linguística ocorrer em uma dada língua e em uma dada época.

Para o estudo de uma variável linguística, é preciso considerar a vida social da comunidade de fala em que ela ocorre. Como exemplifica Labov (2008, p. 188), “[...] uma comunidade de fala não pode ser concebida como um grupo de falantes que usam todos as mesmas formas; ela é mais bem definida como um grupo que compartilha as mesmas normas a respeito da língua”. Em vista disso, a concepção de comunidade adotada a define como um conjunto de falantes que compartilham atitudes sociais a respeito da língua. Ao observar a vida social da comunidade, consideram-se as variáveis extralinguísticas, como escolaridade, sexo/gênero e faixa etária, por exemplo.

\footnotetext{
${ }^{5}$ Essa teoria também é denominada Sociolinguística quantitativa, “[...] por operar com números e tratamento estatístico dos dados coletados" (TARALLO, 2003, p. 8).
} 
A variável escolaridade demonstra a possível influência do grau de instrução do informante na escolha de determinada variante. Em seus estudos, Hora e Henrique (2015) afirmam que essa variável está relacionada ao status de prestígio e conservadorismo de determinadas variantes. Para os autores, falantes com alta escolarização tendem a usar as variantes padrão; já os falantes com baixa escolarização costumam usar formas não-padrão. Em relação ao papel da escola na fala das pessoas, Monaretto (1997) declara que:

[...] constata-se quando se prefere uma forma em detrimento de outra, por ser aquela de mais prestígio, utilizada entre interlocutores de classe social privilegiada, e por não ser estigmatizada, sem despertar uma reação negativa. O ensino, pois, desencadeia um processo de identificação de grupos com base no comportamento dos indivíduos, muitas vezes desastroso. (MONARETTO, 1997, p. 33).

A variável sexo/gênero costuma constatar disparidade entre mulheres e homens no uso da língua. Segundo Labov (2008, p. 282), as mulheres são mais sensíveis às formas prestigiadas e, quando comparadas aos homens do mesmo grupo socioeconômico ao qual pertencem, “[...] se corrigem mais nitidamente do que os homens nos contextos formais”.

Como explicitam Paiva e Duarte (2013), por meio da variável faixa etária, é possível apontar se o fenômeno estudado se trata de variação estável ou mudança em progresso. A variação estável se dá quando duas variantes possuem frequências relativamente próximas em diferentes faixas etárias. A mudança em progresso ocorre quando as gerações mais novas, em comparação às mais velhas, apresentam uma frequência maior no uso de uma variante, o que, com o passar do tempo, resulta na eliminação da outra variante. As autoras ressaltam que a verificação do status da mudança se dá de duas maneiras: (i) pelo estudo em tempo aparente, que consiste em um recorte sincrônico de amostra de fala de pessoas de diferentes faixas etárias; (ii) pelo estudo em tempo real, podendo ser realizado com uma análise de curta duração, em que há um recorte diacrônico de tempo em que os informantes são acompanhados pelo pesquisador, ou de longa duração, em que o fenômeno é analisado por meio de registros seculares a partir de textos escritos. ${ }^{6}$

Como já exposto, as variáveis extralinguísticas influenciam diretamente no uso linguístico e, consequentemente, essa influência será atrelada à categorização social das variantes como padrão/não padrão, conservadora/inovadora e de prestígio/estigmatizada. De modo geral, a variante "[...] considerada padrão é, ao mesmo tempo, conservadora e aquela que goza do prestígio sociolinguístico na comunidade” (TARALLO, 2003, p. 12). É utilizada por uma comunidade de fala que possui prestígio social e teve acesso a uma alta escolarização. A variante não padrão, no entanto, geralmente é utilizada por sujeitos que vivem à margem da sociedade e com menor acesso ao ensino de qualidade. Nesse sentido, seria, ao mesmo tempo, não padrão, inovadora e estigmatizada socialmente.

\footnotetext{
${ }^{6}$ De acordo com Paiva e Duarte (2013), o estudo em tempo real de longa duração apresenta alguns problemas, como, por exemplo, o uso de documentos escritos para a análise do fenômeno, já que não há registros orais de falantes nativos de séculos anteriores. Para as autoras, a dificuldade está em saber se o texto escrito representa a língua usada naquela época, pois esses textos, geralmente, apresentam correções em direção à norma padrão.
} 
Utilizando o arcabouço sociolinguístico apresentado, este trabalho investiga aspectos estruturais e sociais que podem condicionar a aplicação de metátese no interior paulista, fenômeno que costumava - equivocadamente - ser considerado aleatório e irregular (HORA; TELLES; MONARETTO, 2007), e que passa, agora, a ser descrito mais detalhadamente.

\section{Metátese}

A metátese, termo de origem grega que significa transposição, mudança de lado (HORA; TELLES; MONARETTO, 2007), pode ser definida como "fenômeno de troca de posições de um segmento dentro de uma palavra” (CRISTÓFARO SILVA, 2011, p. 152), ou seja, uma “[...] mudança em que os sons trocam de posições com um outro" (HORA; TELLES, 2019, p. 161), como em per.gun.ta pre.gun.ta e vi.dro vri.do. Segundo Silva (2011), a metátese é classificada como um processo de transposição de segmento, seja ele consoante ou vogal, ocorrendo, sobretudo, na fala coloquial, em vocábulos como dren.to $\sim$ den.tro e lar.ga.to la.gar.to.

Essa transposição de segmentos tem, como consequência, a reformulação da(s) sílaba(s) em que esse processo é aplicado, como ocorre em per.gun.tar, em que a vibrante muda de posição na sílaba inicial, ficando pre.gun.tar. Assim sendo, cabe destacar que, quanto à estrutura silábica do português, o presente trabalho segue a proposta de Collischonn (2001), baseada em Selkirk (1982). Nesse modelo, a estrutura silábica é formada por um ataque (A) e uma rima (R), sendo a rima dividida em núcleo (Nu) e coda (Co). Collischonn (2001) afirma que o núcleo é a única posição que deve ser obrigatoriamente preenchida. Esse modelo está exemplificado na Figura 1 a seguir com o verbo obrigar.

Figura 1 - Estrutura silábica
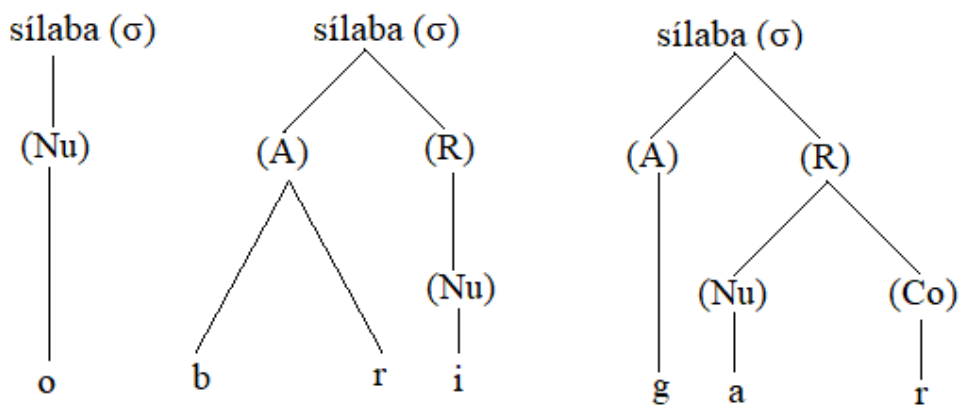

Fonte: Elaborado pelas autoras a partir de Selkirk (1982) e Collischonn (2001).

O ataque pode ser simples, preenchido por uma consoante, ou complexo, com duas consoantes. Collischonn (2001) explica que o ataque complexo no português é constituído por uma obstruinte seguida de uma consoante líquida. ${ }^{7}$ Entretanto, não são todas as combinações de obstruintes + líquidas que são permitidas no português, como destaca a autora.

${ }^{7}$ De acordo com Roberto (2016), as líquidas são um conjunto que engloba vibrantes (/r/) e laterais (/l/ e /K/). 
Segundo Collischonn (2001), por meio da escala de sonoridade (Figura 2), pode-se relacionar um segmento com a posição que ele ocupa na sílaba. Para a autora, o núcleo é ocupado pelo segmento de maior sonoridade, enquanto o ataque e a coda são ocupados pelos elementos de menor sonoridade.

Figura 2 - Escala de sonoridade

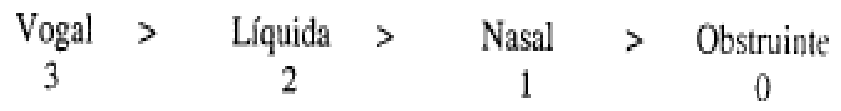

Fonte: Collischonn (2001, p. 101).

O núcleo é, portanto, sempre preenchido por uma vogal. Além disso, quando há mais de um segmento dentro do ataque ou da coda, os segmentos apresentam sonoridade crescente em direção ao núcleo (COLLISCHONN, 2001).

Em relação à representação da regra fonológica que resulta no fenômeno da metátese, há duas maneiras de grafá-la: a formal e a informal. Edwards e Shriberg (1983, apud HORA; TELLES, 2019, p. 161) afirmam que há várias maneiras de representar essa regra, porém a informal mais utilizada pode ser escrita como: C1C2 $\rightarrow$ C2C1. Por sua vez, a regra formal é exposta por Cagliari (2002), que a apresenta, para o vocábulo pirulito, como: [......l...] $\rightarrow$ [...l.......].

Para Hume (2002), a direção da mudança varia de uma língua para a outra, pois uma mesma combinação assume ordens diferentes conforme a língua em uso. Quando observadas interlinguisticamente, algumas combinações de sons resultantes de metátese aparecem em apenas uma ordem. Além disso, as pistas acústicas/auditivas para a identificação das sequências que resultam da metátese são sempre "melhores" do que as da ordem esperada, por serem de mais fácil produção ou percepção (HUME, 2002).

Em seu trabalho, a autora evidencia duas condições que devem ser satisfeitas para que ocorra metátese: ${ }^{8}$ (i) a ambiguidade na combinação dos sons no input; ${ }^{9}$ e (ii) a ordem dos sons oposta àquela do sinal de input deve ser atestada na língua. A primeira prepara o contexto para metátese, enquanto a segunda influencia como o sinal é processado (HUME, 2002). De acordo com Hume (2002), certas combinações de sons têm ordenamento variável em diversas línguas, o que pode acarretar confusão quanto à organização temporal, convergindo, também, nos sons envolvidos na metátese. Para a autora, quando ambos os ordenamentos sonoros envolvidos na metátese são atestados em uma língua, o falante tenderá a produzir o ordenamento com maior frequência nessa língua.

Segundo Araújo (2011), o conhecimento dos padrões sonoros influencia, também, o ordenamento sonoro. Assim sendo, para que ocorra a metátese, segundo a autora, deve haver indeterminância no sinal e a ordem dos elementos oposta à que ocorre no input deve ser observada ou permitida na língua.

Mielke e Hume (2001 apud ARAÚJO, 2011) ressaltam que a metátese não compromete o reconhecimento da palavra, devido à prevalência de ocorrência entre segmentos adjacentes.

\footnotetext{
${ }^{8}$ Como destaca a autora, essas condições são necessárias, mas não suficientes, já que a metátese também pode ser influenciada por fatores cognitivos e sociais.

${ }^{9}$ Input corresponde à forma subjacente, e output, à forma de superfície.
} 
Os autores destacam que esse fenômeno será menos predominante do lado esquerdo do vocábulo, dado que os inícios de palavras tendem a ser “[...] particularmente robustos, capazes de resistir a processos fonológicos e onde, por norma, tanto o acesso lexical como a informação estão ancorados” (MIELKE; HUME, 2001 apud ARAÚJO, 2011, p. 93).

Os pesquisadores sobreditos afirmam que sequências de consoantes favorecem a aplicação da metátese, pois dois sons ocorrendo no mesmo ambiente e com características de produção semelhantes geram pistas acústicas e auditivas semelhantes, dificultando a identificação dos segmentos. Ademais, acrescentam que segmentos com sonoridades similares são a maioria dos casos, diferenciando-se no modo e no ponto de articulação. Grammont (1946 apud HORA; TELLES; MONARETTO, 2007) sugere que os segmentos mais sonoros são transpostos para mais próximos do núcleo silábico, enquanto os menos sonoros para fronteiras silábicas.

Sá Nogueira (1958, apud HORA; TELLES; MONARETTO, 2007) classifica a metátese como progressiva, regressiva e recíproca. A metátese progressiva ocorre quando há o deslocamento do fonema da esquerda para a direita, como, por exemplo, em pra.to pa.tro. A regressiva corresponde à transposição da direita para a esquerda, como ocorre em sa.tis.fa.ção sas.ti.fa.ção. Por fim, quando dois fonemas invertem a posição, ocorre a denominada metátese recíproca, como, por exemplo, em acerola acelora.

A metátese parece ser frequente entre as líquidas e, segundo Brandão e Callou (2019), a troca entre as líquidas, classificada como rotacismo, ${ }^{10}$ pode ocorrer por metátese ou dissimilação. Os casos de rotacismo por metátese dão-se com a inversão das líquidas no vocábulo, isto é, a metátese recíproca, como o exemplo já citado a.ce.ro.la, realizado como a.ce.lo.ra. Em relação às ocorrências de metátese progressiva e regressiva, Hora, Telles e Monaretto (2007) explicitam que há mais casos com as líquidas não laterais, o rótico, como em pre.gui.ça per.gui.ça e es.tu.pro es.tru.po, já que a líquida lateral tende a se vocalizar ${ }^{11}$ em posição de coda no PB.

Blevins e Garret (2004 apud HORA; TELLES, 2019) sugerem a categorização da metátese em quatro tipos:

i. Metátese perceptual, envolvendo traços de longa duração em cadeias multissegmentais que se espraiam sobre uma sequência inteira, possibilitando reinterpretação em posições incomuns, como em per.gun.ta pre.gun.ta.

ii. Metátese compensatória, em que traços de uma sílaba átona deslocam-se para uma sílaba tônica devido ao condicionamento prosódico, como em tá.bua táu.ba.

iii. Metátese auditiva, resultado da separação auditiva do som sibilante do resto da cadeia da fala, como ocorre categoricamente em vocábulos como hizdaken (*hidzaken) ('envelhecer') no hebraico moderno (JONES, 2016).

iv. Metátese coarticulatória, que surge em conjuntos de consoantes com o mesmo modo de articulação, porém pontos de articulação diferentes, como em apkas akpas ('agora'), presentes na língua micronésia mokilesa (BLEVINS; GARRET, 2004 apud JONES, 2016).

\footnotetext{
${ }^{10} \mathrm{O}$ rotacismo consiste na troca do /l/ pelo / $/$ ou vice-versa, fenômeno recorrente na história da língua portuguesa, especialmente no que diz respeito à realização de uma consoante lateral, como em $b / l / u s a$, por uma consoante vibrante, como em $b[r] u s a$ (COSTA, 2007).

${ }^{11}$ Vocalização é a “alteração de uma consoante para vogal” (CRISTÓFARO SILVA, 2011, p. 220), como em me[w] (para mel).
} 
A partir da análise de dados de metátese no PB presentes em diferentes séculos, inclusive no século XXI, Hora, Telles e Monaretto (2007), bem como Hora e Telles (2019), afirmam que não há, no PB, casos de metátese auditiva e coarticulatória.

Quanto à metátese perceptual, os autores observam que envolve o rótico na segunda posição de ataque complexo ou em coda silábica, podendo ocorrer na mesma sílaba (tautossilábica) ou entre sílabas diferentes (heterossilábica). A metátese perceptual tautossilábica, como em car.ví.cu.la cra.ví.cu.la e tro.cer tor.cer, de acordo com os autores, pode ocorrer bidirecionalmente, mas geralmente com movimento à esquerda. Pode ocorrer tanto em sílaba pretônica quanto tônica, mas geralmente no início da palavra, especialmente na primeira sílaba. Em termos de contexto seguinte ao rótico em coda, existe favorecimento da metátese quando a consoante seguinte apresenta o traço [+ contínuo], como em for.ça fro.ça.

Já na metátese perceptual heterossilábica, o rótico pode ocupar as duas posições mencionadas (coda ou ataque), porém preserva sua posição ocupada na sílaba de origem, como em po.bre pro.be e la.gar.to lar.ga.to (HORA; TELLES; MONARETTO, 2007; HORA; TELLES, 2019). Sobre a direcionalidade, tende a se deslocar à esquerda, como mostram os exemplos. Ademais, os autores constatam que o rótico tende a se mover em direção à sílaba tônica em palavras dissílabas, formando ataque complexo. Segundo os autores, exceções a essas regularidades são possíveis, como do.brar $\sim$ dro.bar e es.tu.prar es.tru.par. Os autores também observaram casos de metátese perceptual heterossilábica envolvendo a fricativa alveolar /s/ em vocábulos com mesma base radical, como em sa.tis.fa.ção sas.ti.fa.ção e sa.tis. fei.to sas.ti.fei.to. ${ }^{12}$

Por fim, a metátese compensatória envolve antecipação de vogal alta na penúltima sílaba para a posição de coda de sílaba precedente tônica, como em ar.má.ri.o ar.mái.ro e per.pé.tu.a per.péu.ta. Segundo os autores, trata-se de um processo motivado pelo acento, desfazendo palavras proparoxítonas e hiatos, em prol, respectivamente, de paroxítonas e ditongos.

De modo geral, no que concerne ao PB, Hora, Telles e Monaretto (2007) observam que influenciam a aplicação e a categorização da metátese os seguintes fatores: (i) direção do segmento; (ii) tonicidade do vocábulo; (iii) posição da(s) sílaba(s); e (iv) domínio prosódico. Em relação ao último fator, os autores apontam que a restrição para a ocorrência da metátese é a palavra morfológica, isto é, fronteira de morfema e sequência de palavra e clítico não acarretam metátese.

Em relação a aspectos extralinguísticos, Hora, Telles e Monaretto (2007, p. 187) afirmam que a metátese, no PB, parece estar condicionada pela escolaridade do falante, pois sua aplicação ocorre principalmente no falar de indivíduos pouco escolarizados. Ocorre, também, principalmente em sequências com /p/ e rótico, havendo reestruturação silábica de CCV para CVC, como em pre.ten.der per.ten.der e pre.ci.so per.ci.so, contexto que, segundo os autores, parece sofrer estigma social. Ademais, comparativamente, a partir de dados de fala do Sul do país obtidos no banco de dados Varsul e dados de corpora com amostras do Nordeste, os autores constatam que o fenômeno está mais presente nas variedades do PB faladas no Nordeste do que no Sul.

\footnotetext{
${ }^{12}$ Segundo os autores, para ambos os tipos de metátese perceptual, o processo é bloqueado quando a migração resultar em sequência silábica malformada na língua, como em lar.va *Ira.va e so.frer * sro.fer.
} 


\section{Metátese diacrônica}

Estudos diacrônicos confirmam que a transposição dos segmentos, como em pro.be.za po.bre.za, é um fenômeno antigo na língua portuguesa (ARAÚJO, 2011). Hora, Telles e Monaretto (2007) afirmam que há registros de metátese da passagem do latim para o português. Alguns desses registros se estabilizaram como a única forma de realização, por exemplo: fe.nes.tra fres.ta, outros casos mantiveram as duas formas, por exemplo: en.jo.ar e.no.jar. Apesar de haver registros que mostram a metátese como um importante processo de mudança, segundo Freitas (2005), nem sempre as aplicações resultaram em mudanças definitivas na língua.

Como explicitam Hora, Telles e Monaretto (2007) e Hora e Telles (2019), há ocorrências de metátese na passagem do latim para o português com as consoantes coronais $/ \mathrm{r}, \mathrm{l}, \mathrm{n}, \mathrm{s} /$, vogais, glides e sílabas, como mostra o Quadro 1 a seguir.

Quadro 1 - Exemplos de metátese

\begin{tabular}{|c|c|c|}
\hline Consoantes & Vogais e glides & Entre sílabas \\
\hline semper $>$ sempre & ravia $>$ raiva & chantar $>$ tanchar \\
\hline anhelitu $>$ alento & primariu $>$ primeiro & \\
\hline sibilare $>$ silvar & capio $>$ caibo & \\
\hline
\end{tabular}

Fonte: Elaborada pelas autoras, a partir de Hora, Telles e Monaretto (2007), Hora e Telles (2019) e Bagno (2012).

Como apontam os autores, deve-se destacar o comportamento das consoantes coronais para a realização da metátese, visto que:

A maior parte de casos de reordenamento ocorre ou apenas com o rótico /r/ ou envolvendo o rótico e a lateral /l/, mas há, no português arcaico, a transposição de /d/, como em palude>padule, segundo registra Silva Neto (1956, p. 221). Historicamente, os segmentos $/ \mathrm{l}, \mathrm{r}, \mathrm{n}, \mathrm{d} /$, além de serem os desencadeadores da metátese, são solidários em outros processos fonológicos, como a dissimilação, evidenciando que os sons envolvidos pertencem a uma classe fonológica e que são influenciados por padrões de língua. (HORA; TELLES; MONARETTO, 2007, p. 186).

A partir de dados do português arcaico, destaca-se, particularmente, a recorrência de metátese envolvendo a consoante coronal líquida vibrante. Ali (1968, p. 35) afirma que "frequente no português antigo era a metátese de R”, cuja justificativa era a busca pela adjacência em relação a outras consoantes, como /t, p, f/, como em per.ver.ter $\sim$ pre.ve.ter, tor.cer $\sim$ tro. cer e fer.mo.so fre.mo.so. O autor traz outro exemplo de metátese envolvendo o /r/: a palavra com.pe.tra com.pre.ta, que, em seguida, sofre o processo de lambdacismo, ficando com.ple.ta.

Em um estudo de documentos manuscritos dos séculos XVII, XVIII, XIX e XX, Hora e Telles (2019) investigaram os casos de metátese ocorridos em comparação a dados atuais, em diferentes estados brasileiros, considerando as variedades padrão e não padrão. Como exemplos de aplicações de metátese encontradas pelos autores, têm-se, para a metátese tautossilábica, per.ten.de.rão e pre.mi.tir (séculos XVII a XIX) e per.fe.re e bro.bo.le.ta (dados atuais). Por sua vez, para a metátese heterossilábica, têm-se a.pre.te.xos e lar.ga.ta (séculos XIX e XX, 
respectivamente) e vri.do e car.da.ço (dados atuais). Os autores constataram que a metátese tautossilábica é a mais frequente, tanto na variedade padrão quanto na não padrão, em oposição à metátese heterossilábica, considerada quase inexistente após a ocorrência de apenas um dado, la.gar.ta lar.ga.ta. Por outro lado, ao comparar os dados dos períodos históricos com o período atual, eles observaram "uma incidência considerável de metátese heterossilábica” (HORA; TELLES, 2019, p. 171).

Hora, Telles e Monaretto (2007, p. 189) afirmam que registros de séculos passados de textos oficiais e, portanto, representantes da variedade padrão, indicam que a metátese variável era encontrada inclusive na variedade culta, “[...] particularmente antes da institucionalização do ensino no país, quando fatores externos ganham força na regulação da norma”. Não era, portanto, condicionada por fatores extralinguísticos como escolaridade, por exemplo, diferentemente do que ocorre no PB contemporâneo.

Como já descrito, a metátese é um fenômeno antigo no PB, tendo registro desde a passagem do latim ao português, sendo classificada como um processo de mudança (HORA; TELES, 2019). Apesar de os estudos diacrônicos serem importantes para a observação do fenômeno nos diferentes estágios da língua, esta pesquisa realiza uma análise sincrônica, para verificar o status da metátese como um fenômeno variável presente no PB atual e, ainda, por serem escassos os estudos sincrônicos a respeito desse processo.

Passa-se, na próxima seção, à apresentação do material e dos métodos utilizados durante a condução desta pesquisa.

\section{Material e métodos}

Esta pesquisa analisa ocorrências de metátese na comunidade de fala do interior paulista. A complexa tarefa de obtenção de corpus para a análise sincrônica da metátese, destacada por Araújo (2011, p. 93), torna-se ainda maior quando se busca investigar esse fenômeno a partir de amostras de fala espontânea. Isso se justifica pelo fato já apresentado de a metátese não apresentar um contexto linguístico específico para sua aplicação, como usualmente ocorre com outros processos fonético-fonológicos variáveis (HUME, 2002), como a ditongação diante de /S/ em coda silábica, como em trê[j]s trêØs (CARLOS; CARMO, 2018), e o apagamento de /r/ também em coda, como em fa.la[.] fa.láØ (CARMO; TABORDA, 2019), por exemplo. Assim sendo, para a realização desta pesquisa, fez-se necessária a análise de todos os vocábulos de 48 inquéritos com amostras de fala espontânea do interior paulista.

Essas 48 entrevistas foram extraídas do banco de dados IBORUNA(GONÇALVES, 2021 [2007]), ${ }^{13}$ resultado do Projeto ALIP (Proc. FAPESP 03/08058-6). Sob a coordenação do Prof. Dr. Sebastião Carlos Leite Gonçalves (Ibilce/Unesp), o IBORUNA conta com amostras de fala espontânea de informantes de sete dos 96 municípios que compõem a região administrativa de São José do Rio Preto: Bady Bassit, Cedral, Guapiaçu, Ipiguá, Mirassol, Onda Verde e São José do Rio Preto.

${ }^{13}$ Segundo Gonçalves (2019), Iboruna significa rio preto em Tupi guarani. 
O banco de dados IBORUNA é composto por dois tipos de amostras: (i) Comunidade (ou Censo - AC); e (ii) Interação Dialógica (AI). ${ }^{14}$ Na primeira categoria, foram coletadas amostras de fala espontânea por meio de cinco tipos de relatos:

(i) narrativa de experiência pessoal, envolvendo relatos de fato pessoal alegre ou triste; (ii) narrativa recontada, com reprodução de fato alegre ou triste ocorrido com outrem, sem envolvimento do informante; (iii) texto descritivo, baseado em descrição de local; (iv) relato de procedimentos, baseado em experiências que exijam procedimentos ordenados; (v) relato de opinião, abordando temáticas variadas. (GONÇALVES, 2019, p. 287).

Por sua vez, a AI é constituída por 11 amostras de conversações/diálogos, com dois a cinco informantes, em contextos livres de interação social.

Para este estudo, são utilizadas as entrevistas pertencentes à AC, devido ao fato de, nela, os informantes estarem organizados a partir de sua estratificação social. Para a exequibilidade desta pesquisa, são analisados todos os vocábulos de 48 inquéritos (correspondentes a 31,6\% da $\mathrm{AC}$ e a cerca de 23 horas e 30 minutos de gravação), relativos às seguintes faixas etárias:

i. De 7 a 15 anos (inquéritos AC-001-024).

ii. Acima de 55 anos (inquéritos AC-121-144).

A investigação da variável faixa etária justifica-se com base na hipótese, já apresentada anteriormente, da presença mais frequente da metátese na faixa etária de 7 a 15 anos, por esses falantes ainda não terem atingido o período crítico de aquisição da linguagem (HORA; TELLES, 2019). Para uma análise comparativa, verificou-se, como outro fator investigado, a faixa etária com idade mais avançada, superior a 55 anos.

Além da faixa etária, é considerado, também, o sexo/gênero (feminino e masculino), com base na afirmação de que "[...] diferenciação sexual da fala frequentemente desempenha um papel importante no mecanismo da evolução linguística” (LABOV, 2008, p. 348). Como já mencionado, as mulheres, quando comparadas aos homens, costumam evitar as variantes estigmatizadas socialmente. Assim sendo, por meio da investigação do sexo/gênero, pode-se verificar eventual estigma em relação ao fenômeno variável analisado. ${ }^{15}$

Por fim, considera-se, também, a escolaridade $\left(1^{\circ}\right.$ Ciclo do EF, $2^{\circ}$ Ciclo do EF e Ensino Médio), com base nos estudos de Araújo (2011), Hora e Telles (2019) e Hora, Telles e Monaretto (2007). Historicamente, a metátese costumava ser relacionada unicamente à fala de crianças no período de aquisição da linguagem. Os autores supracitados afirmam, porém, que esse fenômeno é motivado, também, pelo grau de escolaridade do informante. Desse modo, “[...] no PB, parece que o processo de transposição de sons está relacionado à escolarização, principalmente, pois a sua realização ocorre preferencialmente em informantes com poucos anos de escolarização” (HORA; TELLES, 2019, p. 169), tendo em vista que “não se trata da forma padrão” (ARAÚJO,

\footnotetext{
${ }^{14}$ Outras informações estão disponíveis em: https://www.alip.ibilce.unesp.br/. Acesso em: 7 out. 2021.

${ }^{15}$ Cabe destacar que, neste trabalho, segue-se a terminologia utilizada pelo banco de dados IBORUNA para sexo/gênero. Para discussões sobre gênero como construção social e sobre a terminologia sexo/gênero nos estudos sociolinguísticos, recomenda-se a obra de Freitag (2015).
} 
2011, p. 89). A investigação dessa variável visa observar eventual influência da escolaridade na realização da metátese na variedade do interior paulista, podendo apontar, também, indícios de estigma social em relação ao processo. ${ }^{16}$

Quanto às variáveis linguísticas analisadas neste estudo, como apresentado anteriormente, não há um contexto linguístico específico para a aplicação da metátese (HUME, 2002). Apesar disso, com base no referencial teórico apresentado na seção anterior, o presente trabalho investiga a estrutura e a tonicidade silábicas, a direcionalidade da transposição e a classificação fonológica do segmento.

Em relação aos passos metodológicos, após a seleção das 48 amostras pertencentes à AC do banco de dados IBORUNA, com o auxílio dos arquivos de transcrição ortográfica do banco de dados, foi realizada a análise de oitiva dos arquivos sonoros. Cabe destacar que esta pesquisa não conduziu análise acústica por meio de softwares específicos, como o PRAAT (BOERSMA; WEENINK, 2021), pelo fato de o banco de dados IBORUNA não apresentar qualidade suficiente para tal análise. Isso decorre da existência de ruídos nos inquéritos, os quais foram conduzidos a partir de uma metodologia sociolinguística que objetivava coletar o vernáculo do informante, isto é, “[...] a língua falada em situação natural de comunicação” (TARALLO, 2003, p. 88), quando não se policia nem se presta atenção ao modo como se fala. Dessa maneira, as gravações não foram realizadas em cabine com isolamento acústico, e, assim, apresentam ruídos.

Devido ao número de casos de metátese encontrados e à própria natureza do fenômeno, esta pesquisa não é feita nos moldes tradicionais da pesquisa sociolinguística laboviana, não tendo sido utilizado programa estatístico para a análise quantitativa dos dados, por exemplo.

A partir da análise de todos os vocábulos das 48 entrevistas, foram coletadas todas as ocorrências de metátese e, por fim, procedeu-se à tabulação das ocorrências em relação às variáveis extralinguísticas investigadas. Feitos esses procedimentos, foi conduzida a análise dos dados, a qual passa, na próxima seção, a ser apresentada.

\section{Análise dos dados}

Após a análise de todos os vocábulos dos 48 inquéritos analisados, foram encontradas 18 ocorrências de metátese, sendo 17 com o rótico /r/ e um caso envolvendo vogais. Os dados estão apresentados, em ordem alfabética, no Quadro 2.

\footnotetext{
${ }^{16}$ Como explica Carmo (2013), durante a constituição do banco de dados IBORUNA, foram encontradas dificuldades na localização de informantes de determinados perfis sociais. Uma das hipóteses para essa dificuldade seria o entrecruzamento das variáveis renda familiar e escolaridade, “[...] o que fez com que a Coordenação do Projeto ALIP decidisse afrouxar os fatores referentes à variável renda familiar” (CARMO, 2013, p. 112-113). Devido a esse afrouxamento, apesar da consideração de quatro informantes para cada perfil social, a variável renda familiar não é considerada neste estudo.
} 
Quadro 2 - Ocorrências de metátese

\begin{tabular}{|l|l|}
\hline VOCÁBULO & OCORRÊNCIAS \\
\hline A.co.bra.ci.a (a.cro.ba.ci.a) & 2 \\
\hline Co.rá1 ${ }^{17}$ (co.ar) & 1 \\
\hline Dro.mir (dor.mir) & 1 \\
\hline Fi.bra.mol.gi.a (fi.bro.mi.al.gi.a) & 1 \\
\hline Mons.tor (mons.tro) & 1 \\
\hline Po.bre.ma (pro.ble.ma) & 7 \\
\hline Por.por.ção (pro.por.ção) & 1 \\
\hline Pro ou.tro (por ou.tro) ${ }^{18}$ & 1 \\
\hline Pro.que (por.que) & 3 \\
\hline TOTAL & $\mathbf{1 8}$ \\
\hline
\end{tabular}

Fonte: Elaborado pelas autoras.

Dos dados levantados, 17 (94,4\%) correspondem a casos de metátese envolvendo o rótico /r/, como em a.co.bra.ci.a. Esse resultado está em conformidade com a afirmação de Hora, Telles e Monaretto (2007) de que o maior número de casos de transposição de segmento ocorre com o /r/, pois, segundo os autores, a líquida é um dos desencadeadores de metátese, com especial destaque ao rótico, já que a líquida lateral tende a sofrer vocalização em contexto de coda em muitas variedades do PB.

Dos 17 casos de metátese com a líquida não lateral, 76,4\% envolvem, como contexto, os segmentos /t p/, como em por.que pro.que, assim como destacado em relação à metátese diacrônica. Como apresentado, segundo Ali (1968), no português antigo, a metátese com o /r/ era justificada pela busca por adjacência a outras consoantes, como /t p f/, como em per.ver.ter pre.ver.ter, formando, assim, ataque complexo.

Em relação à categorização de Sá Nogueira (1958, apud HORA; TELLES, 2019), que se refere à direção da transposição do segmento no vocábulo, foram encontrados:

i. 11 ocorrências de metátese progressiva, transposição da esquerda para a direita (a.co.bra. ci.a, mons.tor, po.bre.ma e por.por.ção).

ii. Seis casos de metátese regressiva, deslocamento da direita para a esquerda (co.rá, dro.mí, pro ou.tro e pro.que).

iii. Um caso de metátese recíproca, ocorrendo a inversão dos segmentos (fi.bra.mol.gi.a).

Essas ocorrências podem ser mais bem visualizadas no Quadro 3.

\footnotetext{
${ }^{17}$ Realizado foneticamente com o apagamento de /r/ em coda silábica: coráø. Por fugirem do escopo deste trabalho, não estão representadas, no Quadro 2, as aplicações de outros processos fonético-fonológicos nos vocábulos, como o alçamento vocálico (ocorrido, por exemplo, em $d r[u] . m i r)$.

${ }^{18}$ Presente no inquérito AC-130, no trecho "eu gostava de outro, era eu nossa era apaixonada por outro e eu não gostava dele”.
} 
Quadro 3: Casos de metátese de acordo com a direção

\begin{tabular}{|c|c|c|c|c|c|}
\hline \multicolumn{2}{|c|}{ PROGRESSIVA } & \multicolumn{2}{|c|}{ REGRESSIVA } & \multicolumn{2}{|l|}{ RECÍPROCA } \\
\hline Vocábulo & Ocorrências & Vocábulo & Ocorrências & Vocábulo & Ocorrências \\
\hline a.co.bra.ci.a & 2 & co.rá & 1 & \multirow{4}{*}{ fi.bra.mol.gi.a } & \multirow{4}{*}{1} \\
\hline mons.tor & 1 & dro.mir & 1 & & \\
\hline po.bre.ma & 7 & pro ou.tro & 1 & & \\
\hline por.por.ção & 1 & pro.que & 3 & & \\
\hline TOTAL & 11 & TOTAL & 6 & TOTAL & 1 \\
\hline
\end{tabular}

Fonte: Elaborado pelas autoras.

Com a transposição dos segmentos, houve a reestruturação das sílabas envolvidas nos dados classificados como metátese progressiva e regressiva. Nos casos de metátese progressiva, em a.co.bra.ci.a, ocorre a reformulação de duas sílabas, em que a sílaba de origem deixa de apresentar ataque complexo e passa a apresentar ataque simples (cro $>c o$ ) e a sílaba que recebe o segmento deixa de apresentar ataque simples, tornando-se ataque complexo ( $b a>b r a)$; já em mons.tor e por.por.ção, o ataque complexo é desfeito e a posição de coda é preenchida (tro > tor e pro > por), transformando a sílaba aberta em sílaba fechada.

Na última ocorrência de metátese progressiva, po.bre.ma, a transposição desfaz o ataque complexo na sílaba de origem ( $p r o>p o$ ), porém a sílaba que recebe o segmento continua como ataque complexo e o /l/ é substituído pelo [r], processo denominado rotacismo (ble $>$ bre). ${ }^{19}$

Cabe destacar que, como resultado da ressilabação, nos casos em que a metátese desfaz o ataque complexo e preenche a posição de coda, em mons.tor e por.por.ção, o rótico deixa de ser pronunciado foneticamente como tepe e passa a ser realizado como retroflexo, variante utilizada, na variedade analisada, em contexto de coda silábica.

Nas ocorrências de metátese regressiva, em dro.mí, pro ou.tro e pro.que, a reestruturação silábica acontece porque o rótico deixa de preencher a posição de coda e passa a formar um ataque complexo (dor > droØ, por > proØ); no caso de co.rá, o /r/ sai da posição de coda e preenche a posição de ataque, formando um ataque simples (Øar $>$ raØ). Em todos os casos de metátese regressiva, a reformulação altera a estrutura silábica de sílaba travada para livre.

Segundo Collischonn (2001), o ataque complexo no português é formado por uma obstruinte seguida de uma líquida, contudo não são todas as combinações de obstruinte + líquidas que são permitidas. Por isso, é importante ressaltar que, em todos os quatro casos em que a metátese forma o ataque complexo, ocorrem combinações de obstruinte + líquidas permitidas no português: bra (por exemplo, em bra.ço e co.bra), bre (bre.chó e co.bre), dro (dro.ga.ri.a e qua.dro) e pro (pro.te.ger e com.pro).

Outra classificação que deve ser retomada é a de Blevins e Garret (2004 apud HORA; TELLES, 2019), os quais categorizam a metátese em: perceptual; compensatória; auditiva; e coarticulatória.

De acordo com os autores, no PB não há casos de metátese auditiva e coarticulatória. Nos dados encontrados nesta pesquisa, também não há nenhuma ocorrência de metátese

${ }^{19}$ Outra interpretação possível seria a redução da sílaba CCV para CV, seguida de rotacismo na sílaba seguinte. 
compensatória. Das 18 ocorrências, há 17 casos de metátese perceptual, totalizando 94,4\% dos casos. Todos os dados de metátese perceptual são com o rótico /r/, em concordância com a afirmação de Hora e Telles (2019) e Hora, Telles e Monaretto (2007) de que, no PB, há mais casos de metátese perceptual com a líquida não lateral.

Dos 17 casos citados, oito ocorrências correspondem à metátese perceptual tautossilábica e nove, à heterossilábica. Esses casos estão apresentados a seguir.

Quadro 4 - Metátese Perceptual

\begin{tabular}{|c|c|}
\hline TAUTOSSILÁBICA & HETEROSSILÁBICA \\
\hline $\begin{aligned} \text { pro.por.ção } & \sim \text { por.por.ção } \\
\text { mons.tro } & \sim \text { mons.tor } \\
\text { por.que } & \sim \text { pro.que } \\
\text { por ou.tro } & \sim \text { pro ou.tro } \\
\text { dor.mir } & \sim \text { dro.mir } \\
\text { co.ar } & \sim \text { co.rá }\end{aligned}$ & $\begin{array}{c}\text { a.cro.ba.ci. } a \sim \text { a.co.bra.ci.a } \\
\text { pro.ble.ma } \sim \text { po.bre.ma }\end{array}$ \\
\hline
\end{tabular}

Fonte: Elaborado pelas autoras.

Sobre as ocorrências de metátese perceptual tautossilábica, especificamente no que diz respeito à estruturação silábica, em por.por.ção e mons.tor, a metátese ocorre na sílaba átona, reestruturando a sílaba que sofre o processo, desfazendo o ataque complexo e preenchendo a posição de coda (CCV > CVC). No primeiro caso, ocorre em sílaba pretônica inicial, no segundo caso, dá-se a metátese na postônica. Como explicam Hora e Telles (2019), dentre os casos de metátese, é comum a transposição de segmento em sequências /p/ + rótico, resultando na reestruturação silábica de CCV para CVC, contexto que, segundo os autores, parece sofrer estigma social.

Os casos pro.que, pro ou.tro e dru.mi também acontecem em sílaba átona. No que tange a pro outro, a metátese ocorre em um elemento clítico, ${ }^{20}$ que, devido à sua "proeminência acentual fraca” (CRISTÓFARO SILVA, 2011, p. 74), associa-se a um hospedeiro - no caso, o vocábulo subsequente "outro” -, passando a funcionar como uma sílaba pretônica. Nos três dados, a transposição do /r/ desfaz a posição da coda e transforma o ataque simples em ataque complexo (CVC > CCV).

Na palavra co.ar, a metátese ocorre na sílaba tônica, reformulando a estrutura silábica, em que a posição de coda deixa de ser preenchida, e a posição do ataque, subjacentemente vazia, passa a ser ocupada (VC > CV), sendo realizada como co.rá.

Para Hora, Telles e Monaretto (2007) e Hora e Telles (2019), a metátese perceptual tautossilábica pode ocorrer bidirecionalmente, mas geralmente com movimento à esquerda e, preferencialmente, em início de palavra. Os dados apresentados nesta pesquisa, de modo geral, corroboram essa afirmação, posto que a metátese perceptual tautossilábica ocorre em direção tanto para a direita quanto para a esquerda, mas preferencialmente para a esquerda (regressiva), com 75\% dos casos. No que se refere à tonicidade, realiza-se majoritariamente em sílabas átonas, com cinco ocorrências em sílaba átona e uma em sílaba tônica. Em relação à estrutura silábica,

\footnotetext{
${ }^{20}$ Clítico corresponde a um monossílabo átono que apresenta “[...] independência gramatical, mas é fonologicamente dependente de um elemento adjacente” (CRISTÓFARO SILVA, 2011, p. 74).
} 
constatou-se o mesmo número de ocorrências de transposição do segmento que desfez o ataque complexo e ocupou a coda quanto casos em que deixou a coda e formou o ataque complexo. Por fim, verificaram-se 66,6\% casos em sílabas iniciais.

Em relação às ocorrências de metátese perceptual heterossilábica, em a.co.bra.ci.a, a transposição da líquida não lateral preserva a posição de ataque complexo (cro > bra). Nesse caso, as duas sílabas envolvidas são pretônicas e o /r/ se transpõe para a sílaba mais próxima à sílaba tônica.

Nas ocorrências de po.bre.ma, a metátese ocorre quando o segmento /r/ desloca-se para a sílaba tônica, mantendo a posição de ataque complexo ocupada na sílaba inicial (pro > bre). Nesse caso, além da metátese, também há o fenômeno da troca das líquidas, denominado rotacismo. Isso pode ser afirmado tendo em vista que o rótico /r/ não apenas troca de posição, mas também substitui a líquida lateral /l/. Para Brandão e Callou (2019), o rotacismo ocorre por metátese ou dissimilação.

Hora e Telles (2019) e Hora, Telles e Monaretto (2019) explicam que, na metátese perceptual heterossilábica, a transposição do segmento preserva a posição ocupada na sílaba de origem e tende a se deslocar para a esquerda. Em conformidade com essa afirmação, os dados apresentados mostram que foi preservada a posição da sílaba original de ataque complexo, porém a transposição ocorre em direção à direita (progressiva), com 100\% de ocorrências. No que se refere à tonicidade, a líquida não lateral deslocou-se tanto para a sílaba tônica quanto para a sílaba átona.

Tendo em vista o número total de ocorrências, há mais casos de metátese heterossilábica do que tautossilábica nesta pesquisa, ao contrário do que demonstram Hora e Telles (2019), ao realizarem uma análise diacrônica da metátese. No entanto, cabe destacar que sete ocorrências correspondem a um só vocábulo (po.bre.ma), o que aponta para a relevância da frequência (BYBEE, 2001) do item lexical para a variação e mudança do fenômeno investigado, o que é deixado para futuras pesquisas.

Como apresentado, encontrou-se um dado envolvendo vogais, mais especificamente a vogal baixa /a/ e a média-alta posterior /o/, em fi.bra.mol.gi.a para fi.bro.mi.al.gi.a. Nesse caso, partiu-se da hipótese de que o informante considerou as vogais de /mi.al/ como um ditongo crescente /ja/, e, por isso, houve a monotongação desse ditongo. Após a monotongação, ocorreu a inversão dos segmentos, caracterizada como metátese. Ademais, pode ter ocorrido, também, analogia com o vocábulo fibra, de maior frequência na língua portuguesa do que fibromialgia, termo técnico da área da saúde. Hume (2002) destaca que palavras frequentes na língua têm maior probabilidade de serem acessadas mais facilmente, devido à repetição, enquanto palavras menos usadas tendem a perder força e tornam-se mais difíceis de acessar, facilitando o reordenamento. Novamente, ressalta-se que a investigação da atuação da frequência dos itens lexicais em relação à metátese é deixada para estudos futuros.

É importante destacar que a ocorrência de fi.bra.mol.gi.a não pode ser classificada como nenhuma das quatro categorizações (metátese perceptual, compensatória, auditiva e coarticulatória) apresentadas por Blevins e Garret (2004 apud HORA; TELLES, 2019). 
Em relação às variáveis extralinguísticas, as 18 ocorrências foram obtidas nos falares de informantes com os perfis sociais ilustrados no quadro seguinte:

Quadro 5 - Ocorrências de acordo com os perfis sociais

\begin{tabular}{|l|l|l|l|}
\hline DADO & SEXO/GÊNERO & FAIXA ETÁRIA & ESCOLARIDADE \\
\hline A.co.bra.ci.a (a.cro.ba.ci.a) & Masculino & $7-15$ anos & $2^{\circ}$ Ciclo do EF \\
\hline A.co.bra.ci.a (a.cro.ba.ci.a) & Masculino & $7-15$ anos & $2^{\circ}$ Ciclo do EF \\
\hline Co.rá (co.ar) & Feminino & +55 anos & Ensino Médio \\
\hline Dro.mir (dor.mir) & Feminino & $7-15$ anos & $1^{\circ}$ Ciclo do EF \\
\hline Fi.bra.mol.gi.a (fi.bro.mi.al.gi.a) & Feminino & +55 anos & $2^{\circ}$ Ciclo EF \\
\hline Mons.tor (mons.tro) & Masculino & $7-15$ anos & $2^{\circ}$ Ciclo do EF \\
\hline Po.bre.ma (pro.ble.ma) & Masculino & +55 anos & $1^{\circ}$ Ciclo do EF \\
\hline Po.bre.ma (pro.ble.ma) & Masculino & +55 anos & $1^{\circ}$ Ciclo do EF \\
\hline Po.bre.ma (pro.ble.ma) & Masculino & +55 anos & $1^{\circ}$ Ciclo do EF \\
\hline Po.bre.ma (pro.ble.ma) & Masculino & +55 anos & $1^{\circ}$ Ciclo do EF \\
\hline Po.bre.ma (pro.ble.ma) & Masculino & +55 anos & $1^{\circ}$ Ciclo do EF \\
\hline Po.bre.ma (pro.ble.ma) & Masculino & +55 anos & $2^{\circ}$ Ciclo EF \\
\hline Po.bre.ma (pro.ble.ma) & Masculino & +55 anos & Ensino Médio \\
\hline Por.por.ção (pro.por.ção) & Masculino & +55 anos & $1^{\circ}$ Ciclo do EF \\
\hline Pro ou.tro (por ou.tro) & Feminino & +55 anos & $2^{\circ}$ Ciclo EF \\
\hline Pro.que (por.que) & Masculino & +55 anos & $2^{\circ}$ Ciclo EF \\
\hline Pro.que (por.que) & Masculino & +55 anos & $2^{\circ}$ Ciclo EF \\
\hline Pro.que (por.que) & Feminino & +55 anos & Ensino Médio \\
\hline
\end{tabular}

Fonte: Elaborado pelas autoras.

No que tange à variável faixa etária, verificou-se que houve mais ocorrências na fala de informantes com mais de 55 anos (14 ocorrências) do que de informantes entre 7 e 15 anos (quatro ocorrências), com $78 \%$ e 22\%, respectivamente. Esse resultado refuta a hipótese inicial deste trabalho, a saber, a de que a metátese seria mais frequente na fala de pessoas mais jovens. Esse resultado explicita que o fenômeno não está atrelado à aquisição da linguagem. A princípio, poderia indicar, também, que a metátese estaria em desuso na variedade do interior paulista, resultado minimizado pelo número escasso de ocorrências levantadas. Portanto, para a observação mais detalhada do status desse fenômeno como um caso de variação estável ou de mudança em progresso na variedade considerada, faz-se necessária a ampliação do corpus, com a investigação das faixas etárias intermediárias, por exemplo, o que é deixado para futuras pesquisas.

Em relação à variável escolaridade, foram analisados três níveis de escolaridade: (i) primeiro ciclo do EF; (ii) segundo ciclo do EF; e (iii) Ensino Médio. Como resultado, observou-se que a metátese teve frequência maior (oito ocorrências - 44\%) no falar de informantes com o segundo ciclo do EF, seguida por entrevistados com primeiro ciclo do EF (sete ocorrências 39\%), e, por fim, informantes com o Ensino Médio (três ocorrências - 17\%). 
Araújo (2011), Hora e Telles (2019) e Hora, Telles e Monaretto (2007) afirmam que a metátese é motivada pela escolaridade do informante, sendo mais recorrente na fala de informantes menos escolarizados. Na presente pesquisa sobre a variedade do interior paulista, esse resultado é, de certa forma, corroborado, pois houve índices relativamente próximos para os dois ciclos do EF e taxa significativamente menor para o Ensino Médio.

Por sua vez, esse resultado indicia, também, certo grau de estigma social em relação à aplicação da metátese. Deve-se destacar, aqui, que, de acordo com Brandão e Callou (2019), o rotacismo também ocorre por metátese e que, como explica Bagno (2015), fenômenos como rotacismo caracterizam as variedades não-padrão do PB, sendo alvo de preconceito linguístico. Para a confirmação ou refutação dos resultados referentes à escolaridade, recomenda-se a realização de pesquisas futuras, que considerem, por exemplo, informantes analfabetos e com Ensino Superior completo ou em andamento.

No que se refere à variável sexo/gênero, constatou-se que o processo estudado é mais frequente, no corpus analisado, entre informantes do sexo/gênero masculino do que informantes do sexo/gênero feminino, com 13 (72\%) e cinco ocorrências (28\%), respectivamente.

Como explica Labov (2008 [1972]), a variável sexo/gênero possui um papel importante no mecanismo da mudança linguística, uma vez que as mulheres costumam evitar as variantes que sofrem estigma social, quando comparadas aos homens da mesma classe socioeconômica. Como apontado na análise da variável escolaridade, a metátese parece apresentar certo grau de estigma na variedade do interior paulista, resultado corroborado por meio da variável sexo/ gênero, posto que as mulheres aplicam a metátese com menor frequência do que os homens.

Feita a análise dos dados em relação aos contextos linguísticos e extralinguísticos que envolvem as 18 ocorrências deste estudo, parte-se para as considerações finais.

\section{Considerações finais}

Esta pesquisa analisou o fenômeno fonético-fonológico metátese na variedade falada no interior do estado de São Paulo, com o objetivo de verificar possíveis condicionadores linguísticos e extralinguísticos para as ocorrências da metátese.

A literatura compreende a metátese como um fenômeno recorrente na produção da fala de crianças em fase de aquisição da linguagem (HORA; TELLES, 2019), e, a partir dessa afirmação, considerou-se, como hipótese inicial desta pesquisa, a de que esse fenômeno ocorreria com maior frequência na fala de informantes mais jovens, pertencentes à faixa etária de 7 a 15 anos, posto que ainda não atingiram o denominado período crítico de aquisição da linguagem.

Como resultado, foram encontrados 18 casos de metátese nas 48 entrevistas investigadas. Das 18 ocorrências, houve 17 casos envolvendo o rótico /r/ e uma ocorrência com vogais. O resultado referente ao rótico era esperado, posto que, enquanto consoante líquida - assim como a lateral /// -, pode preencher os contextos silábicos tanto de coda quanto de segunda consoante em ataque complexo. A líquida lateral, todavia, tende a ser vocalizada em coda silábica em muitas variedades do $\mathrm{PB}$, como em $a[w] . m a$ e la.te.ra[w], o que pode restringir sua atuação na metátese. 
A partir da classificação de Sá Nogueira (1958 apud HORA; TELES, 2019), encontraram-se 11 ocorrências de metátese progressiva (a.co.bra.ci.a, mons.tor, po.bre.ma e por.por.ção), seis casos de metátese regressiva (co.rá, dro.mí, pro ou.tro e pro.que) e uma ocorrência de metátese recíproca (fi.bra.mol.gi.a).

Já com base na categorização de Blevins e Garret (2004 apud HORA; TELLES, 2019), foram encontradas 17 ocorrências de metátese perceptual, todas com a líquida vibrante /r/, não havendo casos de metátese auditiva, coarticulatória e compensatória. Dos casos citados, oito ocorrências correspondem à metátese perceptual tautossilábica, na mesma sílaba, e nove à metátese perceptual heterossilábica, em sílabas diferentes.

No caso que envolve vogais, fi.bra.mol.gi.a, essa ocorrência não pode ser classificada como nenhuma das quatro categorizações - metátese perceptual, compensatória, auditiva e coarticulatória - apresentadas por Blevins e Garret (2004 apud HORA; TELLES, 2019); a literatura não parece, portanto, conseguir classificar esse dado.

Quanto às variáveis independentes extralinguísticas, foram investigados sexo/gênero, faixa etária e escolaridade. Para o sexo/gênero, verificou-se que houve maior frequência de metátese no falar de informantes do sexo/gênero masculino do que no falar do sexo/gênero feminino. Em relação à variável faixa etária, constatou-se maior aplicação em entrevistados com mais de 55 anos do que de 7 a 15 anos. Esse resultado refuta a hipótese inicial desta pesquisa de que o fenômeno ocorreria sobretudo no falar de informantes da faixa etária mais jovem, ou seja, de 7 a 15 anos. No que se refere à variável escolaridade, houve maior número de casos no falar de informantes com o $2^{\circ}$ Ciclo do EF, seguido pelo $1^{\circ}$ Ciclo.

Os resultados referentes às variáveis extralinguísticas parecem indicar, para o interior paulista, estigma social em relação à metátese, a qual pode estar em vias de desuso. No entanto, para que esses resultados sejam corroborados ou refutados, faz-se necessária uma investigação de um corpus maior, tendo em vista a relativamente baixa produtividade do fenômeno, sendo analisados outros fatores que não foram englobados na presente pesquisa, como o Ensino Superior e as faixas etárias intermediárias, por exemplo.

De qualquer modo, os resultados obtidos explicitam que a metátese não se limita ao processo de aquisição da linguagem e que, embora menos regular do que outros processos fonético-fonológicos variáveis, na variedade analisada, tende a envolver o rótico e acarretar reestruturação silábica. Ao preencher a lacuna em relação à descrição sincrônica da metátese no interior paulista, espera-se que o presente estudo contribua para o mapeamento desse processo no PB contemporâneo e, de forma mais abrangente, para a literatura da área no âmbito de variação e mudança fonético-fonológica da língua portuguesa.

\section{Referências}

ALI, M. S. Gramática Histórica da Língua Portuguesa. São Paulo: Edições Melhoramentos, 1968.

ARAÚJO, M. J. Visão sobre a metátese: da aquisição à linguagem adulta. eLingUp, Porto, v. 3, n. 1, p. 78-99, 2011. 
BAGNO. M. Gramática pedagógica do português brasileiro. São Paulo: Parábola, 2012.

BAGNO, M. Preconceito linguístico. 56. ed. São Paulo: Parábola, 2015.

BOERSMA, P.; WEENINK, D. Praat: doing phonetics by computer [Computer program]. Version 6.1.38. Disponível em: http://www.praat.org/. Acesso em: 10 jan. 2021.

BRANDÃO, S. F.; CALLOU, D. Pressupostos básicos para uma caracterização fonológica do Português Brasileiro. In: HORA, D.; BATTISTI, E.; MONARETTO, V. O. (coord.). História do português brasileiro: mudança fônica do português brasileiro. São Paulo: Contexto, 2019. p. 34-59.

BYBEE, J. B. Phonology and Language Use. Cambridge: Cambridge University Press, 2001.

CAGLIARI, L. C. Análise fonológica: introdução à teoria e à prática, com especial destaque para o modelo fonêmico. Campinas: Mercado de Letras, 2002.

CARLOS, V. G.; CARMO, M. C. Ditongação variável diante de /S/ em coda silábica na fronteira Brasil/Paraguai. Diadorim, Rio de Janeiro, v. 20, n. 2, p. 238-254, jul./dez. 2018.

CARMO, M. C. As vogais médias pretônicas na variedade do interior paulista. 2013. 249 f. Tese (Doutorado em Estudos Linguísticos) - Universidade Estadual Paulista "Júlio de Mesquita Filho”, São José do Rio Preto, 2013.

CARMO, M. C.; TABORDA, I. R. Apagamento de /R/ em coda silábica na variedade do interior paulista. Letras Escreve, Macapá, v. 9, n. 3, p. 39-51, jul./dez. 2019.

COLLISCHONN, G. A sílaba no português. In: BISOL, L. Introdução a estudos de fonologia do português brasileiro. 3. ed. Porto Alegre: Edipucrs, 2001. p. 91-123.

COSTA, L. T. Análise variacionista do rotacismo. Revista Virtual de Estudos a Linguagem - ReVEL, [s. 1.], v. 5, n. 9, p. 1-29, 2007.

CRISTÓFARO SILVA, T. Dicionário de Fonética e Fonologia. São Paulo: Contexto, 2011.

DIAS, J. A. Acobracias da língua(gem): a metátese no noroeste paulista. 2020. 54 f. Trabalho de Conclusão de Curso (Licenciatura em Letras) - Universidade Estadual de Ponta Grossa, Ponta Grossa, 2020.

FREITAG, R. M. K. (Re)discutindo sexo/gênero na Sociolinguística. In: FREITAG, R. M. K.; Severo, C. G. (org.). Mulheres, Linguagem e Poder: Estudos de Gênero na Sociolinguística Brasileira. São Paulo: Blucher, 2015. p. 17-74.

FREITAS, M. M. Metátese e hipértese em manuscritos do século XVIII. Filologia Linguística Portuguesa, São Paulo, n. 7, p. 119-128, 2005. DOI: https://doi.org/10.11606/issn.2176-9419. v0i7p119-128 
GONÇALVES, S. C. L. Banco de dados Iboruna: amostras eletrônicas do português falado no interior paulista. Disponível em: https://www.alip.ibilce.unesp.br/. Acesso em: 7 out. 2021 [2007].

GONÇALVES, S. C. L. Projeto ALIP (Amostra Linguística do Interior Paulista) e banco de dados Iboruna: 10 anos de contribuição com a descrição do português brasileiro. Revista Estudos Linguísticos, São Carlos, v. 48, n. 1, p. 276-297, abr. 2019. DOI: https://doi. org/10.21165/el.v48i1.2430

HORA, D.; HENRIQUE, P. F. L. Como as restrições sociais e estruturais compõem a identidade do falante. Letras de Hoje, Porto Alegre, v. 50, p. 96-104, dez. 2015.

HORA, D.; TELLES, S. Metátese. In: HORA, D.; BATTISTI, E.; MONARETTO, V. O. (coord.). História do português brasileiro: mudança fônica do português brasileiro. São Paulo: Contexto, 2019. p. 160-177.

HORA, D.; TElleS, S.; MONARETTO, V. N. O. Português brasileiro: uma língua de metátese? Letras de Hoje, Porto Alegre, v. 42, n. 2, p. 178-196, 2007.

HUME, E. Predicting metathesis: the ambiguity/attestation model. Mid-Continental Workshop on Phonology, Indiana University, 2002.

JONES, K. S. Metathesis of Stop-Sibilant Clusters in Modern Hebrew: A perceptual investigation. Tucson: The University of Arizona, 2016.

LABOV, W. Padrões sociolinguísticos. Tradução Marcos Bagno, Maria Marta Scherre e Caroline Rodrigues Cardoso. São Paulo: Parábola, 2008.

LIMA JÚNIOR, R. M. A hipótese do período crítico na aquisição de língua materna. Revista (Con)Textos Linguísticos, Vitória, v. 7, n. 9, p. 225-239, 2013.

MONARETTO, V. N. O. Um reestudo da vibrante: análise variacionista e fonológica. 1997. 213 f. Tese (Doutorado em Letras) - Pontifícia Universidade Católica do Rio Grande do Sul, Porto Alegre, 1997.

NARO, A. J. O dinamismo das línguas. In: MOLLICA, M. C.; BRAGA, M. L. (org.). Introdução à sociolinguística: o tratamento da variação. 4. ed. São Paulo: Contexto, 2013. p. 43-50.

PAIVA, M. C.; DUARTE, M. E. L. Mudança linguística: observações no tempo real. In: MOLLICA, M. C.; BRAGA, M. L. (org.). Introdução à sociolinguística: o tratamento da variação. 4. ed. São Paulo: Contexto, 2013. p. 179-190.

ROBERTO, M. Fonologia, fonética e ensino: guia introdutório. São Paulo: Parábola, 2016.

SELKIRK, E. The Syllable. In: HULST, H.; SMITH, N. (ed.). The Structure of Phonological Representations (Part II). Dordrecht: Foris, 1982. p. 337-383.

SILVA, F. M. Processos fonológicos segmentais na língua portuguesa. Littera, São Luis, v. 2, n. 4, p. 72-88, 2011. 
TARALLO, F. A pesquisa sociolinguística. 7. ed. São Paulo: Ática, 2003.

WEINREICH, U.; LABOV, W.; HERZOG, M. I. Fundamentos empíricos para uma teoria da mudança linguística. Tradução Marcos Bagno. São Paulo: Parábola, 2006. 